\section{Why do people with mental handicap come to a psychiatrist?}

DEAR SIRS

Today the statement that mentally handicapped people do not need psychiatry is often made. Like most generalisations it is true in the sense that it can be seen to apply to the majority of people with mental handicap. In practice mentally handicapped people continue to be referred to psychiatric consultation specialists and clinics. This letter presents a review of a six months analysis of the people newly referred to a psychiatric consultation service for mental handicap.

In the period studied, 1 January to 30 June 1987 , one consultant psychiatrist was serving the whole population of 700,000 in the combined Leeds Western and Leeds Eastern Health Districts. As one consultant saw all the referrals to the mental handicap service, recording was consistent.

Eighteen new patients (ten male, eight female) who had not previously been seen by a psychiatrist in mental handicap, were referred in the period investigated. Nine of these referrals were in the 16 to 29 age group, confirming that this is a time of life during which mentally handicapped people, their families and carers, face difficulties. For example, mentally handicapped adolescents are reaching adulthood, adjusting from schools to training centres, trying to prove themselves and to test others, and their parents are growing older and are feeling the strain of years of caring for them.

One referral was aged under 16 , three were in the 50 to 59 age group, one was over 60 . Eleven patients (seven male, four female) were referred by family doctors, two men through the Community Mental Handicap Teams and five (one man, four women) from other hospitals and specialists. In terms of intellectual classification (ICD-9) three were profoundly, four severely, three moderately and eight (four male, four female) mildly mentally retarded. The high proportion $(44 \%)$ of people with mild handicap reflected the expectation that the consultation service had a duty to receive all categories of mental handicap. Nine patients (seven male, two female) were referred on account of behavioural disorders. They exhibited what fashion now labels "challenging behaviours" with histories of aggressiveness, violence and self injury. Six (three men, three women) came for general advice and were welcomed as their referrals recognised that the psychiatric consultation service had a co-ordinating role in mobilising help, education and preventive action.

Three women were referred with the request for hospital admission. One was already in a hospital for mental handicap elsewhere. The others had been admitted to general hospital wards and were considered too dependent to return to existing community care facilities.

Of the 18 patients seen, six (two male, four female) suffered from epilepsy, a frequency of one in three, to be expected among a sample of mentally handicapped people. Remarkable was the frequency of medical conditions found in the patients examined. Specific disorders were autism, hydrocephalus, cerebral palsy, Sturge Weber Syndrome, Moebius Syndrome, dystrophia myotonica, fibrocystic disease and diabetes mellitus. One patient had hypothyroidism, epilepsy and a calcified meningioma. Another patient had mental illness co-existing with mental handicap.

This study indicated that the cases of mental handicap referred to a psychiatric consultation service presented their own distinct needs and challenges. These called for knowledge, understanding and experience on the part of the specialist. What is now called "The Psychiatry of Mental Handicap" or "Psychiatry in Mental Handicap" emerged as a specific area of psychiatric specialisation. It provided mentally handicapped patients, their family doctors and carers, with advice, assistance and services specifically intended to meet their needs.

Meanwood Park Hospital
Leeds

D. A. SPENCER

\section{Section 37 of the Mental Health Act 1983 DEAR Sirs}

Through your columns I wish to highlight what appears to be a serious anomaly in the Mental Health Act 1983.

Recently I had a patient under my care who was detained in hospital under Section 37 of the Mental Health Act. Within a few days of his being detained I received a letter from the Hospital Managers stating that the patient had applied to them to be discharged from hospital, and asking me to provide a psychiatric report.

I was naturally quite surprised as my understanding was that a patient on this order could not apply to the Mental Health Review Tribunal within the first period of detention. The Act states quite clearly that a patient detained in hospital under Section 37 may apply to a tribunal in the second six months of detention and has a further right within each subsequent period that the detention is renewed.

On querying the matter with the Managers I was told that although a patient could not apply to the MHRT within the first period of detention, he could do so to the Managers of the hospital. They also referred me to a booklet called Hearing Patients' Appeals published by the National Association of Health Authorities. According to this booklet, "A patient detained under Section 37 of the Mental Health Act can appeal to the Managers within the first six months of detention but can appeal to the MHRT only after that first six months."

I later discussed this matter with the Mental Health Act Commission. They agreed that the Act was somewhat ambiguous as to the question of whether a patient on a Section 37 could appeal to the Managers of the hospital within the first six months or not, but suggested that I speak to my Defence Society.

My enquiries with my Defence Society did not take me much further. They initially were quite certain that the patient could not appeal within the first six months. However, when I told them about the NAHA booklet they 